\title{
PERANCANGAN ENTERPRISE ARSITEKTUR TEKNOLOGI INFORMASI MENGGUNAKAN FRAMEWORK TOGAF PADA KOPERASI BUDI KARYA
}

\author{
(Design of Enterprise Architecture Information Technology Using TOGAF on Koperasi \\ Budi Karya)
}

\author{
Arvini Anindhita, Royana Afwani", Ida Bagus Ketut Widiartha \\ Program Studi teknik Informatika, Fakultas Teknik, Universitas Mataram \\ Jl. Majapahit 62, Mataram, Lombok NTB, INDONESIA \\ Email: anindhitaarvini@gmail.com, royana@unram.ac.id, widi@unram.ac.id
}

\begin{abstract}
This study discusses the design of information technology enterprise architecture in the cooperation of Budi Karya. The main problem encountered is that the management still uses manual system. The information obtained in each section has not been integrated with other, the IT management organization structure is not sufficient because there is no staff who have specialized IT experts, and require development in information technology. This was stated in one of the Budi Karya cooperation missions which read "Adopting the development of information technology and modern management systems". This study aims to produce process architecture, data, applications and technology that can be a reference for implementing all activities in cooperation of Budi Karya. This research uses the TOGAF (the Open Group Architecture Framework) which is a framework that has detailed methods and tools for developing and implementing enterprise architecture. Data collection is done by direct observation interviews and literature studies. The results of all these phases will produce a detailed framework of process architecture, data architecture, application architecture, and architecture in cooperation of Budi Karya
\end{abstract}

Keywords: Enterprise, Architecture, Cooperation, framework, TOGAF

*Penulis Korespondensi

\section{Pendahuluan}

Koperasi adalah sebuah organisasi ekonomi yang dimiliki dan dioperasikan oleh orang-seorang demi kepentingan bersama [1]. Koperasi Budi Karya didirikan pada tanggal 7 Mei 2003 dengan Badan Hukum 518/024/BH/DISKOP\&PKM/2003 yang dikeluarkan oleh Dinas Koperasi Kota Mataram. Koperasi Budi Karya merupakan badan usaha yang bergerak di bidang simpan pinjam yang mempunyai tugas pokok untuk mengelola penerimaan anggota baru, mengelola simpan pinjam anggota, dan manajemen keuangan serta membuat laporan simpan pinjam. Akan tetapi diketahui bahwa pengelolaan data di koperasi Budi Karya masih menggunakan cara pembukuan (manual). Seiring Dengan bertambahnya jumlah anggota secara terus menerus namun jumlah karyawan koperasi yang tidak bertambah, maka akan akan menyebabkan ketidakseimbangan untuk pelayanan pada anggota. Selain itu, saat ini informasi yang didapat pada setiap bagian belum saling terintegrasi antara divisi simpan pinjam, divisi usaha dan divisi jasa.
Pada koperasi Budi Karya struktur organisasi pengelola TI belum memadai karena belum adanya staff yang menjadi ahli TI secara khusus, serta belum adanya panduan atau referensi dalam pengelolaan TI. Koperasi Budi Karya juga masih membutuhkan pengembangan dalam bidang teknologi informasi, hal ini tertuang pada salah satu misi Koperasi Budi Karya yang berbunyi "Mengadopsi perkembangan teknologi informasi dan sistem manajemen modern". Berdasarkan misi tersebut serta belum tersedianya dukungan peran dari teknologi informasi yang dapat memudahkan dalam mengakses data serta informasi.

Berdasarkan masalah yang telah dijelaskan, dibutuhkan peranan dari Enterprise Architecture (EA) yang mendukung aktifitas bisnis utama serta bisnis pendukung yang dilakukan oleh Koperasi Budi Karya, sehingga perancangan teknologi informasi ini dapat digunakan untuk meminimalisir kerugian dan masalah yang akan terjadi kedepannya. EA adalah kumpulan dari metode, model, dan prinsip yang digunakan dalam membuat rancangan dan merealisasiskan teknologi informasi, proses bisnis, struktur organisasi, dan infrastrukturnya. Metode lain yang bisa digunakan dalam perancangan arsitektur enterprise 
diantaranya adalah TOGAF, Zachman framework, FEAF, GARTNER dan lain - lain [2].

TOGAF merupakan sebuah framework yang memiliki metode dan tools yang detail untuk mengembangkan dan mengimplementasikan enterprise architecture. Kelebihan TOGAF dibandingkan dengan framework lain adalah memberikan pendekatan yang lebih luas terhadap perancangan, perencanaan, pelaksanaan, dan tata kelola arsitektur informasi.

Berdasarkan permasalahan yang diuraikan dan kebutuhan pada objek penelitian, maka pada penelitian ini akan dilakukan Perancangan Enterprise Arsitektur Teknologi Informasi Menggunakan Framework TOGAF Pada Koperasi Budi Karya. Tujuan dari penelitian ini untuk menghasilkan arsitektur proses, data, aplikasi, dan teknologi yang dapat menjadi acuan pelaksanaan semua aktifitas pada Koperasi Budi Karya.

\section{TINJAUAN PUSTAKA}

Penelitian yang dilakukan menggunakan kerangka kerja TOGAF ADM dalam merencanakan arsitektur perusahaan di rumah sakit umum daerah (RSUD) Murjani. Penelitian ini bertujuan untuk pembuatan dokumentasi terkait pengembangan sistem informasi untuk pelayanan terintegrasi di poliklinik rawat jalan, pelayanan rawat inap dan pelayanan farmasi. Hasil dari penelitian ini menghasilkan blueprint EA dimana saran yang diberikan adalah diharapkannya adanya aspek implementasi, identifikasi parameter strategis untuk perubahan, perhitungan biaya serta rencana implementasi secara keseluruhan [3].

Penelitian yang dilakukan menggunakan framework TOGAF dalam merancang perencanaan arsitektur enterprise sistem informasi pada RSIA Andini. Penelitian ini bertujuan untuk pendefinisian yang jelas tentang arsitektur data, proses, dan jaringan sistem informasi pada proses bisnis yang diperlukan dalam proses pelayanan. Hasil dari penelitian tugas akhir ini adalah menghasilkan model dan kerangka dasar (blueprint) yang digunakan dalam mengembangkan sistem informasi yang terintegrasi untuk mendukung kebutuhan organisasi di RSIA Andini [4].

Penelitian lainnya yaitu yang dilakukan pada KPS Bogor dan pada Dinas Kebudayaan DIY, dimana keduanya menggunakan framework Zachman untuk merancang arsitektur enterprise. Hasil penelitian menunjukkan rekomendasi yang terdiri atas arsitektur data, arsitektur aplikasi, dan arsitektur teknologi. Ketiga data arsitektur tersebut dapat digunakan untuk perancangan arsitektur enterprise [5]. Kemudian, arsitektur enterprise yang dibangun dapat digunakan untuk mendukung proses bisnis sehingga terwujudnya keselarasan antara teknologi informasi dan kebutuhan bisnis [6].

Berdasarkan tinjauan pustaka penelitian diatas yang membahas mengenai perancangan arsitektur enterprise pada berbagai jenis perusahaan/instansi maka penulis menyimpulkan bahwa Framework TOGAF merupakan metode yang dapat digunakan untuk melakukan perancangan arsitektur teknologi informasi.

\section{Metode Penelitian}

Pada penelitian ini akan dilakukan perancangan enterprise architecture teknologi informasi pada Koperasi Budi Karya menggunakan framework TOGAF. Pada Gambar 1 berikut dapat dilihat urutan langkah penelitian :

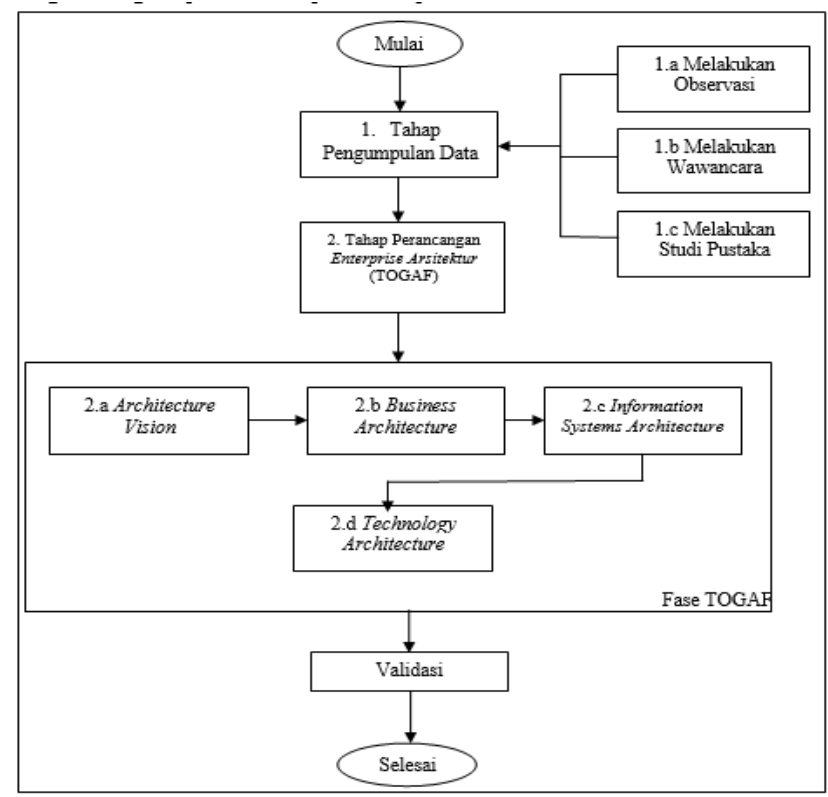

Gambar 1. Tahapan Penelitian

\subsection{Metode Pengumpulan Data}

Penelitian ini menggunakan metode observasi, wawancara, dan studi pustaka dalam pengumpulan data yang dilakukan.

1. Metode Observasi

Obrservasi ini dilakukan dengan melihat sejarah, visi, misi struktur organisasi, AD/ART dan dokumen Proposal Lembaga Pengelola Dana Bergulir Koperasi Pegawai Republik Indonesia (LPDB KPRI) yang ada pada Koperasi Budi Karya.

2. Metode Wawancara

Wawancara dilakukan dengan bertanya langsung kepada ketua Koperasi Budi Karya Bapak Dedy 
Wahyuddin untuk mendapatkan informasi yang berkaitan dengan proses bisnis Koperasi Budi Karya.

3. Metode Studi Pustaka

Pada metode ini dilakukan pengumpulan informasi yang dibutuhkan yang berasal dari buku-buku, publikasi, dan artikel ilmiah.

\subsection{Tahap Perancangan Enterprise Arsitektur Menggunakan TOGAF}

Untuk tahapan perancangan arsitektur teknologi informasi menggunakan metodologi TOGAF. Terdapat 9 fase yang ada pada TOGAF dan pada penelitian ini membahas fase 1 - 4 untuk menentukan kebutuhan arsitektur enterprise pada koperasi. Berikut tahapan perancangan arsitektur teknologi informasi menggunakan framework TOGAF berdasarkan kebutuhan bisnis pada Koperasi Budi Karya.

\subsection{Architecture Vision (Phase A)}

Tahap Architecture Vision menggambarkan batasan dari rancangan arsitektur dengan mendefinisikan ruang lingkup yang memaparkan profil perusahaan, visi misi perusahaan, dan struktur organisasi perusahaan.

\section{Profil Koperasi Budi Karya}

Koperasi Budi Karya didirikan pada tanggal 7 Mei 2003 Jalan Panjitilar Negara No. 8 dengan BADAN HUKUM 518/024/BH/DISKOP\&PKM/2003 yang dikeluarkan oleh Dinas Koperasi Kota Mataram. Koperasi Budi Karya pada saat ini beranggotakan 105 orang yang terdiri dari anggota yang berstatus PNS adalah 76 orang dan Honorer berjumlah 29 orang. Koperasi Budi Karya ingin mengembangkan usaha yang selalu bersentuhan langsung dengan kebutuhan anggota maupun masyarakat secara langsung.

\section{Visi Misi Koperasi Budi Karya}

\section{- Visi}

Terwujudnya kesejahteraan melalui wadah koperasi yang dikelola secara profesional berdasarkan nilai luhur kehidupan dan prinsip koperasi

- Misi

> Menjalankan kegiatan usaha simpan pinjam dengan efektif, efisien dan transparan

$>$ Memberikan bimbingan dari aspek keuangan maupun menejemen kepada anggota yang mempunyai usaha, sebagai binaan koperasi

> Meningkatkan kualitas pelayanan melalui peningkatan kualitas SDM dan iklim organisasi yang kondusif.
Mengadopsi perkembangan teknologi informasi dan sistem manajemen modern

$>$ Menjadi unit usaha simpan pinjam percontohan

3. Struktur organisasi pada Koperasi Budi Karya

Pada struktur organisasi Koperasi Budi Karya menunjukan bagian yang mewakili aktifitas bisnis yang dapat menentukan proses bisnis pada koperasi Budi Karya.

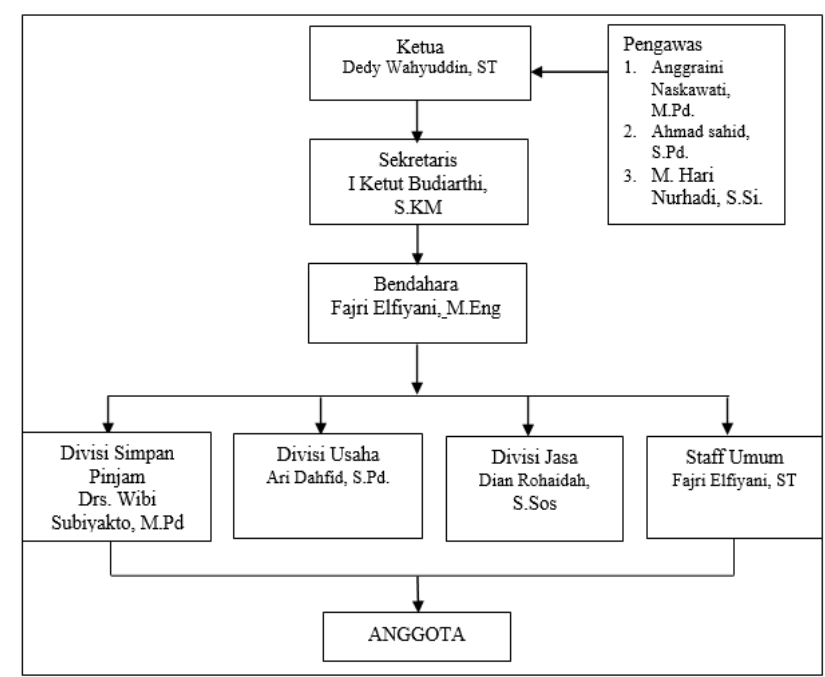

Gambar 2. Struktur Organisasi Koperasi Budi Karya

Koperasi Budi Karya mengepalai sekretaris, bendahara, pengawas, divisi Simpan Pinjam, divisi Usaha, Divisi Jasa, Staff dan anggota Koperasi Budi Karya serta memiliki pengawas.

\section{Analisis Value Chain}

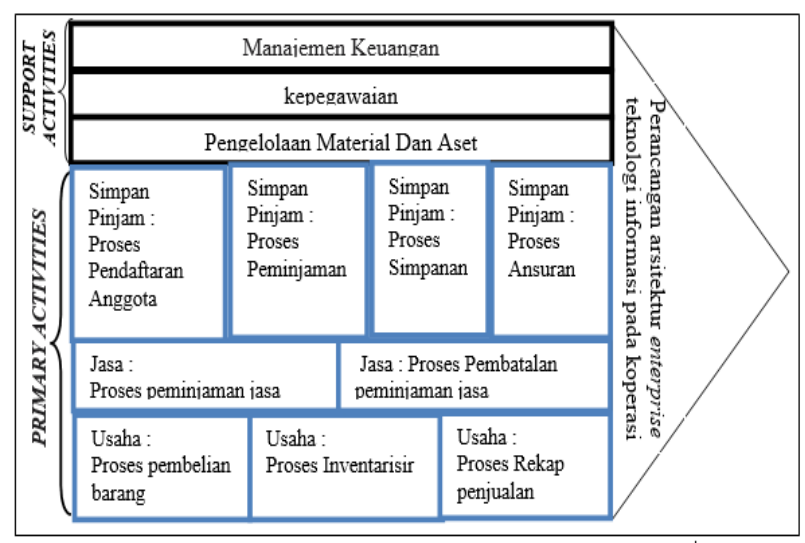

Gambar 3. Analisis Value Chain pada Koperasi Budi Karya

Terdapat dua (2) aktifitas yang terdapat pada koperasi Budi Karya yaitu, aktifitas utama (primary activities) dan Aktifitas pendukung (support activities). Aktifitas utama (primary activities) pada koperasi Budi 
Karya adalah proses pendaftaran anggota, proses peminjaman, proses simpanan, proses angsuran dan proses pengunduran anggota, proses peminjaman jasa, proses pembatalan peminjaman jasa, proses pembelian. Sedangkan untuk Aktifitas pendukung (support activities) adalah kegiatan yang mendukung aktifitas utama, tidak terlibat langsung dalam proses bisnis namun memiliki potensi meningkatkan efisiensi dan efektifitas. Untuk aktifitas pendukung yang ada pada Koperasi Budi Karya adalah manajemen keuangan, kepegawaian dan yang terakhir pengelolaan material dan aset barang, proses inventarisir dan proses rekap penjualan.

\section{Struktur Organisasi Usulan}

Struktur organisasi usulan merupakan hasil analisis dari Value Chain. Jika ditinjau dari struktur organisasi saat ini, Koperasi Budi Karya belum memiliki bagian atau subbagian untuk fokus menangani implementasi arsitektur - arsitektur yang akan dibuat maka peran bagian IT sangat dibutuhkan untuk keberlangsungan proses implementasi arsitektur enterprise pada koperasi Budi Karya. Berikut adalah usulan dari struktur organisasi Koperasi Budi Karya

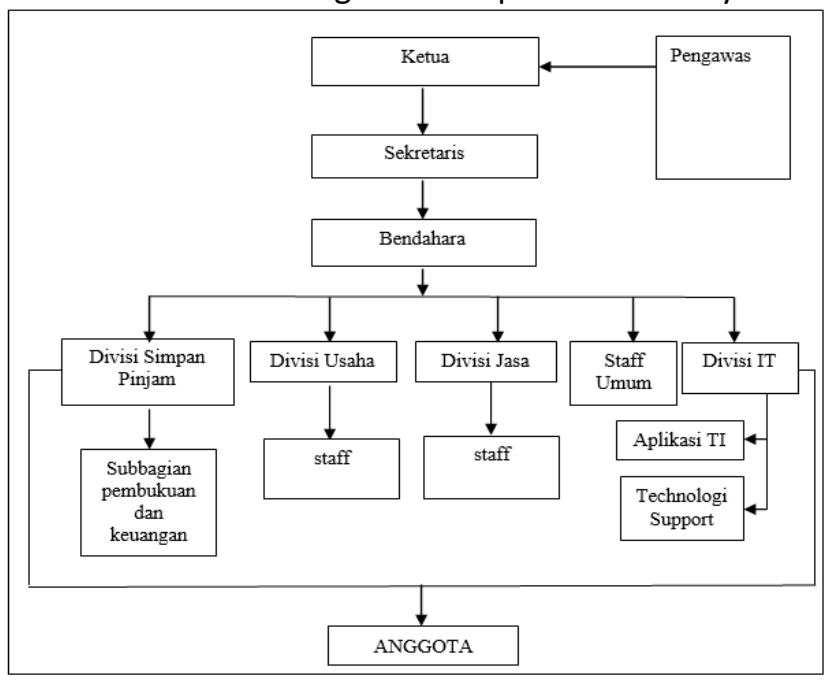

Gambar 4. Struktur Organisasi usulan

Untuk penambahan setiap subbagian berdasarkan struktur organisasi lama maka diusulkan struktur organisasi baru. Penambahan jabatan fungsional untuk meringankan beban kerja sehingga lebih spesifik, membantu meringankan beban kerja setiap divisi serta meningkatkan layanan secara efektif dan efisien sehingga sesuai dengan tujuan bisnis. Penambahan staff tersebut terdiri dari Subbagian pembukuan dan keuangan, staff umum dan divisi IT
6. Usulan Pelatihan

TABEL I. USULAN PELATIHAN

\begin{tabular}{|l|l|l|}
\hline No & \multicolumn{1}{|c|}{ Jabatan } & \multicolumn{1}{c|}{ Jenis Pelatihan } \\
\hline 1. & Aplikasi TI & $\begin{array}{l}\text { Pelatihan untuk mengembangkan kemampuan programming } \\
\text { dalam mengembangkan aplikasi dan mengembangkan } \\
\text { kemampuan analisis dan perencanaan sistem. }\end{array}$ \\
\hline 2. & $\begin{array}{l}\text { Teknologi } \\
\text { Support }\end{array}$ & $\begin{array}{l}\text { Pelatihan untuk mengembangkan kemampuan dalam } \\
\text { mengoperasikan dan memelihara sistem, mengembangkan } \\
\text { kemampuan dalam mengelola keamanan sistem dan untuk } \\
\text { melindungi sistem informasi dari hal - hal yang dapat } \\
\text { merusak informasi, mengembangkan kemampuan dalam } \\
\text { memberi pelatihan kepada end user serta mengembangkan } \\
\text { kemampuan dalam mengatur pengaduan dari end user } \\
\text { mengenai kendala dalam penggunaan sistem }\end{array}$ \\
\hline
\end{tabular}

Tujuan usulan pelatihan untuk memperoleh dan meningkatkan kemampuan yang diperlukan untuk melakukan suatu pekerjaan.

7. Hubungan Stakeholder dan Aktivitas pada Koperasi Budi Karya

TABEL II. STAKEHOLDER PADA KOPERASI BUDI KARYA

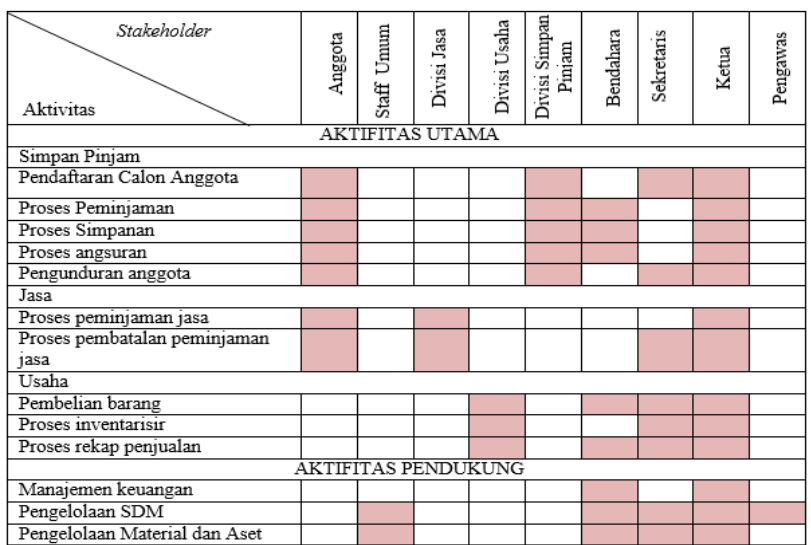

Dalam Stakeholder Koperasi Budi Karya ini terdapat tiga belas (13) aktifitas yang berkaitan dengan Stakeholder tersebut. Namun tidak semua Stakeholder terkait dengan aktivitas yang ada. Jika dilihat dari tabel diatas, ketua adalah Stakeholder yang memiliki keterkaitan dengan semua aktifitas pada koperasi, karena semua aktifitas harus diverifikasi oleh ketua koperasi. Lalu pengawas adalah stakeholder yang memiliki keterkaitan paling sedikit dengan aktifitas di koperasi.

\section{Artifacts phase $\mathrm{A}$}

Artifacts Phase A (Architecture Vision) terdiri dari Solution Concept Diagram. Kedua Artifacts tersebut menggambarkan analisis dari semua phase A yang sudah dilakukan. Berikut penjelasan dari Artifacts solution concept diagram tersebut. 


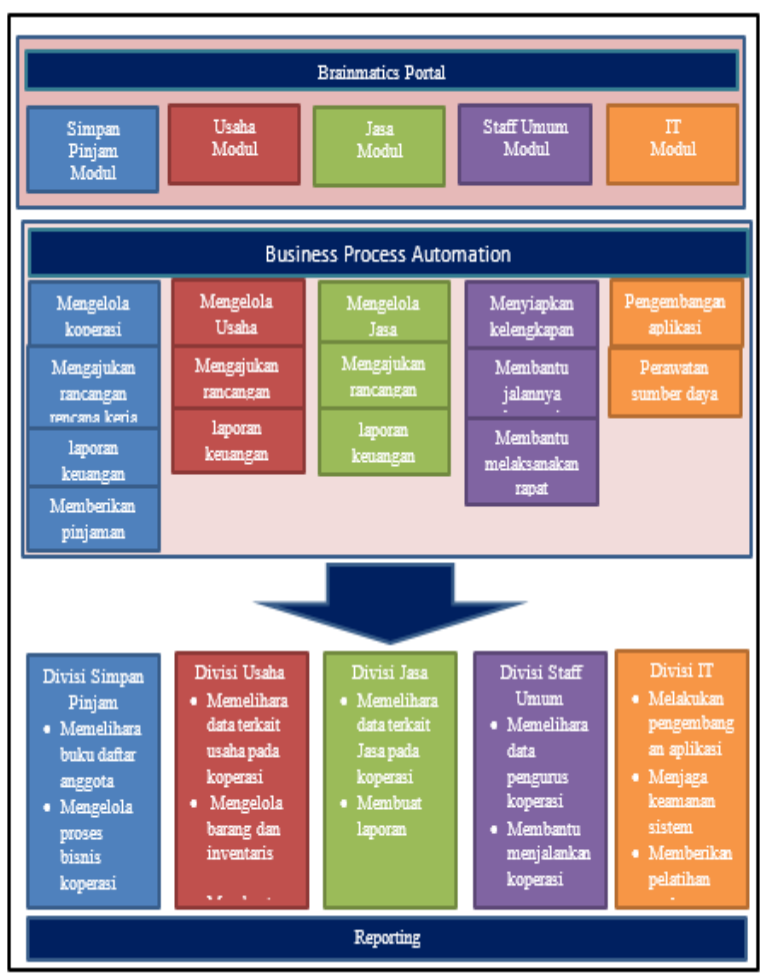

Gambar 5. Solution Concept Diagram [10].

Pada gambar Solution Concept Diagram diatas terdapat 3 bagian yaitu, brainmatics portal, business process automation dan reporting. Solution concept Diagram mengacu pada struktur organisasi usulan yang dibuat pada phase A. pada brainmatics portal merupakan setiap divisi yang ada pada struktur organisasi usulan di koperasi. Sedangkan business process automation merupakan gambaran proses bisnis secara umum setiap divisi yang ada pada koperasi. Yang terakhir reporting menggambarkan proses bisnis secara khusus setiap divisi yang ada pada koperasi koperasi budi karya.

\subsection{Business Architecture (Phase B)}

Aktifitas bisnis Koperasi baik berpedoman pada Angaran Dasar dan Anggaran Rumah Tangga (AD/ART) serta SOP organisasi. Fungsi bisnis utama Koperasi meliputi Unit Simpan Pinjam, Unit usaha, dan Unit Jasa, sedangkan fungsi bisnis pendukung dari fungsi bisnis utama meliputi managemen keuangan, pengelolaan SDM, pengelolaan material dan asset.

1. Pemetaan Layanan bisnis, proses bisnis dan fungsi bisnis

Layanan koperasi adalah jenis bisnis yang dilakukan oleh koperasi Budi Karya. Pada bagian kedua adalah proses bisnis menggambarkan bagaimana koperasi berinteraksi dengan anggota, terdapat tiga (3) proses bisnis pada diagram tree diatas yaitu, pelayanan simpan pinjam, pelayanan usaha dan pelayanan jasa. Pada bagian terakhir terdapat fungsi bisnis yang menunjang agar setiap proses bisnis dapat berjalan. Seperti pada proses bisnis simpan pinjam terdapat fungsi bisnis pendaftaran anggota, pembuatan laporan data anggota dan pembuatan laporan rekapan pendaftaran anggota.

\section{Rancangan Arsitektur aktifitas di Koperasi}

Pada Koperasi Budi Karya terdapat 9 rancangan arsitektur aktifitas yang terdiri dari pendaftaran anggota, pinjaman, simpanan, angsuran, peminjaman jasa, pembatalan peminjaman jasa, invetarisir barang, pembelian barang dan terakhir rekap penjualan. Berikut salah satu contoh rancangan arsitektur aktifitas yang ada di koperasi Budi Karya tersebut.

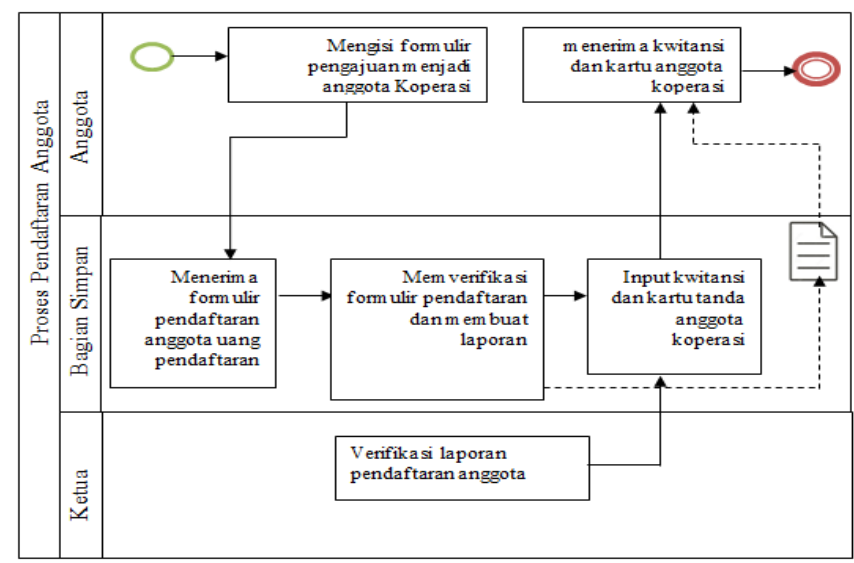

Gambar 6. Rancangan arsitektur aktifitas Peminjaman

Rancangan arsitektur bisnis pendaftaran anggota akan mengubah pendaftaran dan pencatatan data yang masih manual menjadi sistem terkomputerisasi melalui aplikasi pendaftaran . Bagian Simpan Pinjam dan ketua yang terlibat dalam sistem aplikasi pendaftaran anggota harus melakukan login terlebih dahulu. Bagian Simpan Pinjam akan menginput data calon anggota, melakukan pengecekan administrasi. Kemudian sistem akan menghasilkan laporan data anggota yang diinput untuk diproses dan dilaporkan ke ketua untuk memverifikasi pendaftaran anggota tersebut. berikut alur dalam rancangan sistem pendaftaran tersebut.

\section{Analisis actor/role matrix}

Analisis actor/role matrix akan menjelaskan tentang peranan Stakeholder terhadap aktifitas aktifitas yang ada di Koperasi Budi karya. 
TABEL III. ACTOR / ROLE MATRIX

\begin{tabular}{|c|c|c|c|c|c|c|c|c|c|}
\hline $\begin{array}{l}\text { RACI } \\
R=\text { melakukan suatu kegiatan } \\
\mathrm{A}=\text { bertanggung jawab dan memiliki } \\
\text { otoritas memutuskan perkara } \\
\mathrm{C}=\text { diperlukan sarannya dan } \\
\text { berkontribusi terhadap kegiatan } \\
\mathrm{I}=\text { perlu tahu hasil dari suatu } \\
\text { putusan tindakan }\end{array}$ & $\begin{array}{l}\text { 范 } \\
\text { o } \\
\text { 品 }\end{array}$ & 虫 & 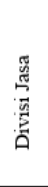 & 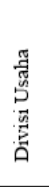 & 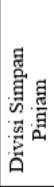 & 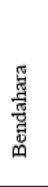 & 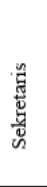 & 妥 & 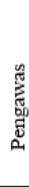 \\
\hline \multicolumn{10}{|c|}{ Simpan Pinjam } \\
\hline Pendaftaran Calon Anggota & $\mathrm{R}$ & & & & $\mathrm{RC}$ & & $\mathrm{AI}$ & AI & I \\
\hline Proses Peminjaman & $\mathrm{R}$ & & & & $\mathrm{RC}$ & $\mathrm{AI}$ & & AI & I \\
\hline Proses Simpanan & $\mathrm{R}$ & & & & $\mathrm{RC}$ & AI & & AI & I \\
\hline Proses angsuran & $\mathrm{R}$ & & & & $\mathrm{RC}$ & $\mathrm{AI}$ & & AI & I \\
\hline Pengunduran anggota & $\mathrm{R}$ & & & & $\mathrm{RC}$ & & $\mathrm{AI}$ & AI & I \\
\hline \multicolumn{10}{|c|}{ Jasa } \\
\hline Proses peminjaman jasa & $\mathrm{R}$ & $\mathrm{R}$ & $\mathrm{RC}$ & & & & $\mathrm{CI}$ & AI & I \\
\hline $\begin{array}{l}\text { Proses pembatalan peminjaman } \\
\text { jasa }\end{array}$ & $\mathrm{R}$ & $\mathrm{R}$ & $\mathrm{RC}$ & & & & $\mathrm{CI}$ & $\mathrm{AI}$ & I \\
\hline \multicolumn{10}{|c|}{ Usaha } \\
\hline Pembelian barang & & $\mathrm{R}$ & & $\mathrm{RC}$ & & $\mathrm{CI}$ & & $\mathrm{AI}$ & I \\
\hline Proses inventarisir & & $\mathrm{R}$ & & $\mathrm{RC}$ & & $\mathrm{CI}$ & & AI & I \\
\hline Proses rekap penjualan & & $\mathrm{R}$ & & $\mathrm{RC}$ & & $\mathrm{CI}$ & & $\mathrm{AI}$ & I \\
\hline
\end{tabular}

Berdasarkan TABEL III yang telah dibuat, keterangan Responsible merupakan peranan dari divisi Simpan Pinjam, Divisi Jasa dan Divisi Usaha dan staff karena divisi terseut mengerjakan pekerjaan secara langsung dalam setiap aktifitas. Keterangan Accountable merupakan peranan dari ketua karena ketua, sekretaris dan bendahara yang bertanggung jawab terhadap aktifitas yang dilakukan oleh divisi lain dan mereka juga memiliki otoritas untuk pengambilan keputusan dalam setiap aktifitas. Keterangan Consulted merupakan peranan dari ketua dan pengawas koperasi Budi Karya karena semua masukan mereka sangat diperlukan sebagai bahan pertimbangan untuk pengambilan keputusan. Keterangan informed juga merupakan peranan dari ketua koperasi Budi Karya karena perlu mengetahui segala laporan kegiatan yang terjadi di koperasi Budi Karya.

\section{ARTIFACTS PHASE $B$}

Artifacts Phase B (Business Architecture) terdiri dari Functional Decomposition Diagram. Artifacts tersebut menggambarkan analisis dari semua phase $\mathrm{B}$ yang sudah dilakukan. Tujuan dari Functional Decomposition Diagram adalah untuk menggambarkan kemampuan organisasi berdasarkan pada arsitektur. Dengan memeriksa kemampuan suatu organisasi dari perspektif fungsional.

\section{Hasil Penelitian}

\subsection{Hasil Penelitian dengan togaf}

Dalam bab ini akan membahas phase lanjutan dari bab sebelumnya, dimana pada bab sebelumnya telah membahas 2 phase TOGAF yaitu, Architecture Vision dan Business Architecture. Pada phase kedua yaitu business architecture membahas mengenai pemetaan layanan bisnis, proses bisnis dan fungsi bisnis, serta rancangan arsitektur aktifitas dan analisis actor/role matrix di koperasi Budi Karya.

Maka untuk melengkapi proses atau phase yang telah dilakukan, maka akan dibahas 2 phase TOGAF lanjutan yaitu phase information system architecture yang di bagi menjadi arsitektur aplikasi dan arsitektur data serta phase technology architecture.

\subsection{INFORMATION SYSTEM ARCHITECTURE (PHASE C)}

Pada phase arsitektur sistem informasi ini membahas megenai arsitektur data dan arsitektur aplikasi yang berdasarkan dari hasil keluaran arsitektur bisnis yang telah dibuat. Dalam phase $\mathrm{C}$ membahas mengenai bagaimana arsitektur sistem informasi dibangun.

\subsubsection{ARSITEKTUR ARSITEKTUR APLIKASI}

Terdapat 9 rancangan arsitektur aplikasi yang dibutuhkan olek Koperasi Budi Karya yaitu aplikasi pendaftaran anggota, aplikasi peminjaman, aplikasi simpanan, aplikasi angsuran, aplikasi peminjaman jasa, aplikasi pembatalan peminjaman, aplikasi pembelian barang, aplikasi inventarisir dan aplikasi rekap penjualan.

\subsubsection{ARSITEKTUR APLIKASI SIMPAN PINJAM}

Pada Koperasi Budi Karya terdapat 9 rancangan arsitektur aplikasi yang terdiri dari pendaftaran anggota, pinjaman, simpanan, angsuran, peminjaman jasa, pembatalan peminjaman jasa, invetarisir barang, pembelian barang dan terakhir rekap penjualan. Salah satu contoh rancangan use case aplikasi yang ada pada koperasi Budi Karya tersebut adalah aplikasi jasa yang memiliki 4 actor dan 7 use case yang terlibat. Actor yang terlibat yaitu anggota, admin jasa dan ketua. Use case yang terlibat yaitu login, kelola data anggota peminjaman jasa, kelola data peminjaman jasa, cetak data peminjaman jasa, laporan peminjaman jasa, kelola data pembatalan peminjaman jasa dan laporan pembatalan peminjaman jasa. Use case login melibatkan actor yaitu admin jasa dan ketua. Admin jasa mengelola use case kelola data anggota peminjaman jasa, kelola data peminjaman jasa, cetak data peminjaman jasa, laporan peminjaman jasa, kelola data pembatalan peminjaman jasa dan laporan pembatalan peminjaman jasa. Ketua dapat mengelola use case laporan peminjaman jasa dan laporan pembatalan peminjaman jasa. Untuk anggota dapat mengelola use case cetak data peminjaman dan kelola data pembatalan peminjaman.

\subsubsection{ARSITEKTUR DATA}

Perancangan arsitektur data dilakukan untuk menggambarkan entitas data yang berhubungan dengan Koperasi Budi Karya. Terdapat beberapa 
rancangan arsitektur data yang dibutuhkan oleh Koperasi Budi Karya, yaitu sistem pendaftaran anggota, sistem peminjaman, sistem simpanan, sistem pembayaran angsuran, sistem peminjaman jasa, sistem pembatalan peminjaman jasa, sistem inventarisir barang, sistem pembelian barang dan yang terakhir sistem rekap penjualan.

\subsubsection{ARSITEKTUR DATA PADA KOPERASI BUDI KARYA}

Pada Koperasi Budi Karya terdapat 9 rancangan arsitektur aplikasi yang terdiri dari pendaftaran anggota, pinjaman, simpanan, angsuran, peminjaman jasa, pembatalan peminjaman jasa, invetarisir barang, pembelian barang dan terakhir rekap penjualan. Berikut salah satu contoh rancangan arsitektur aplikasi yang ada di koperasi Budi Karya tersebut.

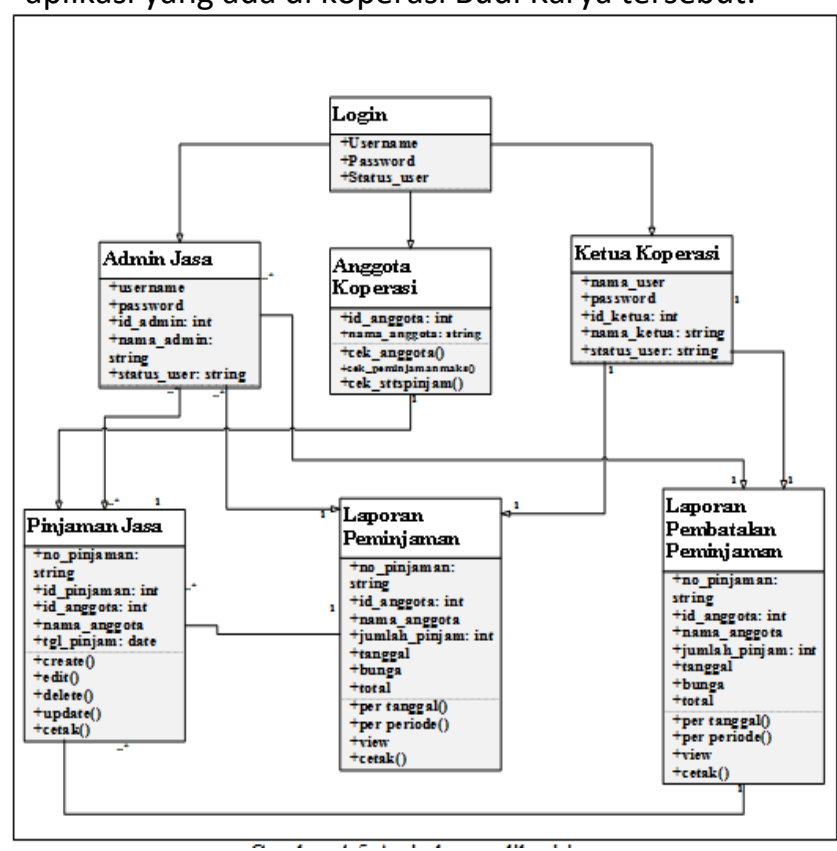

Gambar 7. Arsitektur data Jasa

Arsitektur data aplikasi jasa memiliki 7 kelas yaitu, login, admin jasa, ketua, anggota koperasi, pinjaman jasa, laporan peminjaman dan laporan pembatalan peminjaman.

\subsubsection{ARTIFACTS PHASE C}

Artifacts Phase C (Information System Architecture) terdiri dari Application Portfolio Catalog (baseline), Baseline Application Architecture dan Application Use case Diagram: Global Package. Artifacts tersebut menggambarkan analisis dari semua phase $\mathrm{C}$ yang sudah dilakukan. Berikut penjelasan dari ketiga Artifacts tersebut.

\subsubsection{1 application Portfolio Catalog (baseline)}

Application Portfolio Catalog merupakan sebuah cara untuk mengklasifikasikan aplikasi - aplikasi yang digunakan oleh suatu organisasi atau perusahaan kedalam kelompok tertentu agar dapat dimanfaatkan dengan efektif dan efisien dan sesuai dengan fungsi bisnis pada organisasi tersebut. Dalam Application Portfolio Catalog dibawah ini terdapat beberapa aplikasi yang telah dikelompokkan sesuai dengan fungsi bisnisnya. Berikut tabel Application Portfolio Catalog pada koperasi Budi Karya tersebut

tABEL IV. Application Portfolio Catalog

\begin{tabular}{|c|l|}
\hline \multicolumn{1}{|c|}{ Organization } & \multicolumn{1}{|c|}{ Application } \\
\hline \multirow{4}{*}{ Divisi Simpan Pinjam } & Pendaftaran Anggota \\
\cline { 2 - 3 } & Aplikasi Peminjaman \\
\cline { 2 - 3 } & Aplikasi Simpanan \\
\cline { 2 - 3 } & Aplikasi angsuran \\
\hline \multirow{2}{*}{ Divisi Usaha } & Peminjamanjasa \\
\cline { 2 - 2 } & Pembatalan Peminjamanjasa \\
\hline \multirow{2}{*}{ Divisi Jasa } & Invetarisir barang \\
\cline { 2 - 2 } & Pembelian barang \\
\cline { 2 - 2 } & Rekap penjualan \\
\hline & Portal informasi Koperasi Budi Karya \\
\hline
\end{tabular}

\subsubsection{BASELINE APPLICATION ARCHITECTURE}

Baseline application berikut ini menampilkan arsitektur aplikasi dasar yang ada pada koperasi Budi Karya. Pada baseline application architecture dibawah menunjukkan terdapat 9 aplikasi yang terhubung pada 3 database. Aplikasi tersebut adalah aplikasi pendaftaran anggota, aplikasi peminjaman, aplikasi simpanan dan aplikasi angsuran yang terhubung dengan DBMS 1. Untuk aplikasi peminjaman jasa dan pembatalan peminjaman jasa terhubung dengan DBMS 2. Sedangkan aplikasi inventarisir barang, pembelian barang dan rekap perjualan terhubung pada DBMS 2.

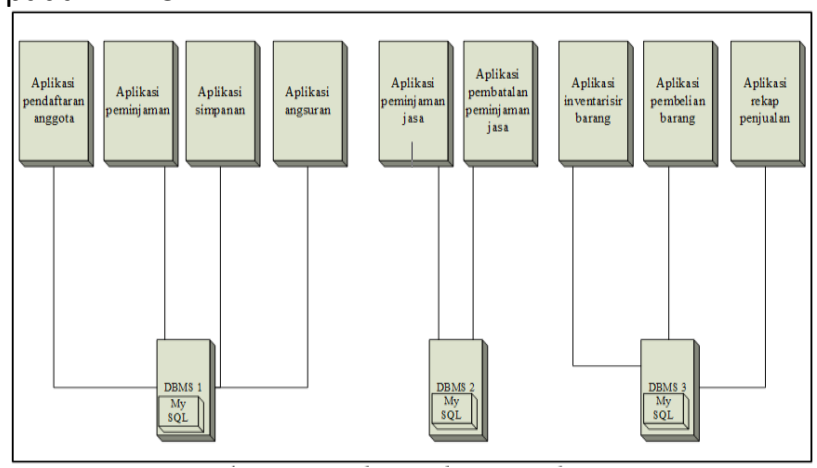

Gambar 8. Baseline Application Architecture [10] 


\subsubsection{Application USE case Diagram: Global PACKAGE}

Pada application use case diagram digambarkan kumpulan use case yang dijadikan satu kesatuan dan ditampilkan dalam bentuk class diagram. Dalam application use case diagram terdapat 9 use case yang ditampilkan yaitu pendaftaran anggota, peminjaman, simpanan, angsuran, peminjaman jasa, pembatalan peminjaman jasa, inventarisir barang, pembelian barang dan rekap penjualan.

\subsection{Technology ARChitecture (Phase D)}

Arsitektur teknologi menggambarkan mengenai jaringan, hardware dan software digunakan pada suatu perusahaan untuk menunjang pelayanan, arus data dan informasi, serta aplikasi yang menunjang aktifitas dan proses bisnis di Koperasi Budi Karya.

\subsubsection{JARINGAN USULAN}

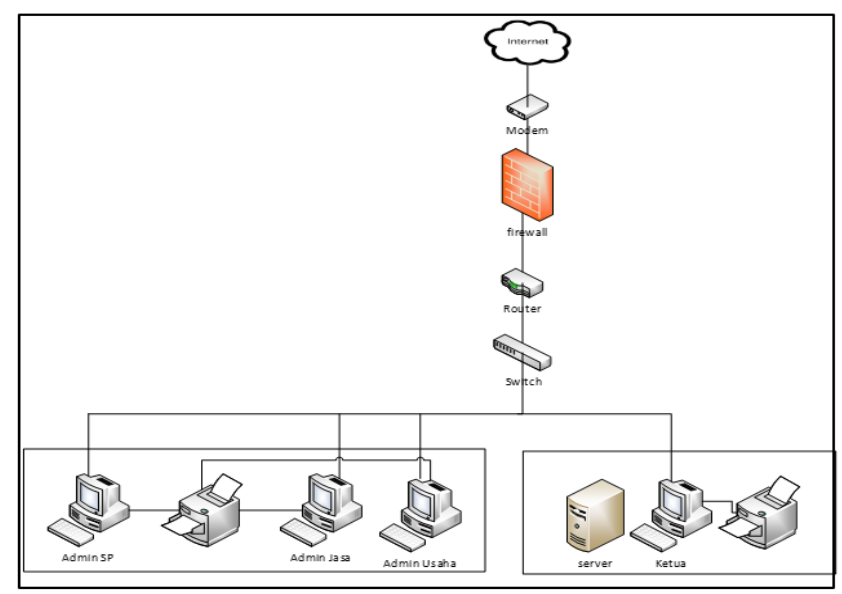

Gambar 9. Jaringan Usulan

Pada gambar 12 menggambarkan jaringan usulan di Koperasi Budi Karya. Ruangan 1 terhubung menggunakan switch dan ruangan 2 terhubung dengan menggunakan switch. Pada ruangan 1 terdapat 3 pc yang digunakan masing - masing admin pada Koperasi Budi Karya yaitu, admin simpan pinjam, admin jasa dan admin usaha yang masing - masing komputer tersebut terhubung pada 1 printer yang akan digunakan bersama. Pada ruangan kedua hanya terdapat 1 komputer yang digunakan Ketua Koperasi untuk mengecek semua laporan kegiatan dan proses bisnis pada Koperasi Budi karya.

\subsubsection{KONFIGURASI JARINGAN, HARDWARE DAN SOFTWARE}

Berikut usulan hardware dan software yang akan digunakan di Koperasi Budi Karya tersebut.

- Berikut Usulan Konfigurasi Jaringan
TABEL V. KONFIGURASI HARDWARE

\begin{tabular}{|l|l|}
\hline \multicolumn{1}{|c|}{ Hardware } & \multicolumn{1}{c|}{ Spesifikasi } \\
\hline Modem & Modem Astinet \\
\hline Router & Router Wireless \\
\hline Switch & 8 port \\
\hline
\end{tabular}

- Berikut usulan konfigurasi hardware

TABEL VI. KONFIGURASI HARDWARE SERVER

\begin{tabular}{|l|l|}
\hline \multicolumn{1}{|c|}{ Hardware } & \multicolumn{1}{c|}{ Spesifikasi } \\
\hline Server & Hp ProLiant ML350pG8 \\
\hline Prosessor & Intel xeon E5-2620 \\
\hline Memory & 8 GB DDR 3 - 1333 \\
\hline Storage & 1 Terra Byte \\
\hline Input device & Mouse, keyboard \\
\hline Output device & Monitor LCD \\
\hline
\end{tabular}

TABEL VII. KONFIGURASI HARDWARE CLIENT

\begin{tabular}{|l|l|}
\hline \multicolumn{1}{|c|}{ Hardware } & \multicolumn{1}{c|}{ Spesifikasi } \\
\hline Prosessor & Intel Core 2 Duo \\
\hline Memory & 4 GB DDR 3 - 1333 \\
\hline Storage & $500 \mathrm{~GB}$ \\
\hline Input device & Mouse, keyboard \\
\hline Output device & Monitor LCD \\
\hline
\end{tabular}

- Berikut usulan konfigurasi software

TABEL VIII. KONFIGURASI SOFTWARE SERVER

\begin{tabular}{|l|l|}
\hline \multicolumn{1}{|c|}{ Software } & \multicolumn{1}{c|}{ Spesifikasi } \\
\hline Operating System & Windows server 2012 \\
\hline Web Server & apache \\
\hline Web Browser & Google Chorme, Mozila Firefox \\
\hline DBMS & MySQL \\
\hline Word Processing & Microsoft word 2016 \\
\hline
\end{tabular}

TABEL IX. Konfigurasi SOFTWARE CLIENT

\begin{tabular}{|l|l|}
\hline \multicolumn{1}{|c|}{ Sofware } & \multicolumn{1}{c|}{ Spesifikasi } \\
\hline Operating System & Windows server 2012 \\
\hline Web Server & apache \\
\hline Web Browser & Google Chorme, Mozila Firefox \\
\hline DBMS & MySQL \\
\hline
\end{tabular}

\subsubsection{TECHNOLOGY PORTOFOLIO CATALOG}

Technology portofolio catalog digunakan mengindentifikasi daftar infrastruktur hardware, software dan jaringan dalam arsitektur teknologi pada Koperasi Budi Karya. Dalam technology portofolio catalog akan menggambarkan keterkaitan antara domain dengan aplikasi yang telah diusulkan pada koperasi Budi Karya. 
tABel X. Technology Portofolio Catalog

\begin{tabular}{|c|c|c|c|c|c|c|c|c|c|c|}
\hline & 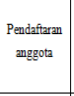 & naming & Simpun & Angsura & 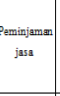 & 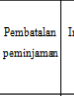 & $\begin{array}{c}\text { Invetarist } \\
\text { beans }\end{array}$ & $\begin{array}{c}\text { Pamblia } \\
\text { barmg }\end{array}$ & 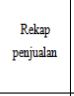 & 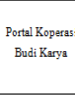 \\
\hline Presenation & 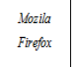 & $\begin{array}{l}\text { Marid } \\
\text { Frafole }\end{array}$ & $\begin{array}{l}\text { Marial } \\
\text { Fropox }\end{array}$ & $\begin{array}{l}\text { Weala } \\
\text { Fraglex }\end{array}$ & $\begin{array}{l}\text { Marile } \\
\text { Frogefe }\end{array}$ & $\begin{array}{l}\text { Weila } \\
\text { Froged }\end{array}$ & $\begin{array}{l}\text { Maila } \\
\text { Frofox }\end{array}$ & $\begin{array}{l}\text { Macila } \\
\text { Fryogx }\end{array}$ & 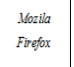 & Annolid \\
\hline DBMS & 1.5S5QL & 1,5002 & .1502 & .1.550L & 1.5092 & .1.5SQL & 1.5092 & 1.5802 & 1.5522 & Oracle \\
\hline 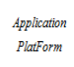 & 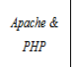 & 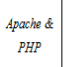 & 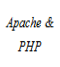 & 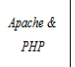 & 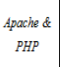 & 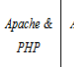 & 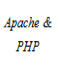 & 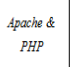 & 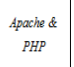 & Jana \\
\hline Lan & Ëhement & Eubrentat & Entwnet & Enhernet & Ehbernat & Ehoment & Ëhrmat & Eüurmet & Ë̈ünat & Intemet \\
\hline $\begin{array}{l}\text { Seartion } \\
\text { Neworort }\end{array}$ & Froveall & Froveall & Frowall & Frowall & Froveral & Froveral & Froveal & Froveall & Froveall & \\
\hline
\end{tabular}

\subsubsection{ARTIFACTS PHASE D}

Artifacts Phase D (Technology Architecture) terdiri dari platform decomposition diagram. Artifacts tersebut menggambarkan analisis dari semua phase D yang sudah dilakukan. Tujuan dari platform decomposition diagram adalah untuk menggambarkan kemampuan berdasarkan arsitektur teknologi. Pada platform decomposition diagram meliputi client interface, presentation, network, network security, application dan database yang akan diusulkan pada Karya Koperasi Budi. Berikut gambaran dari Artifacts tersebut

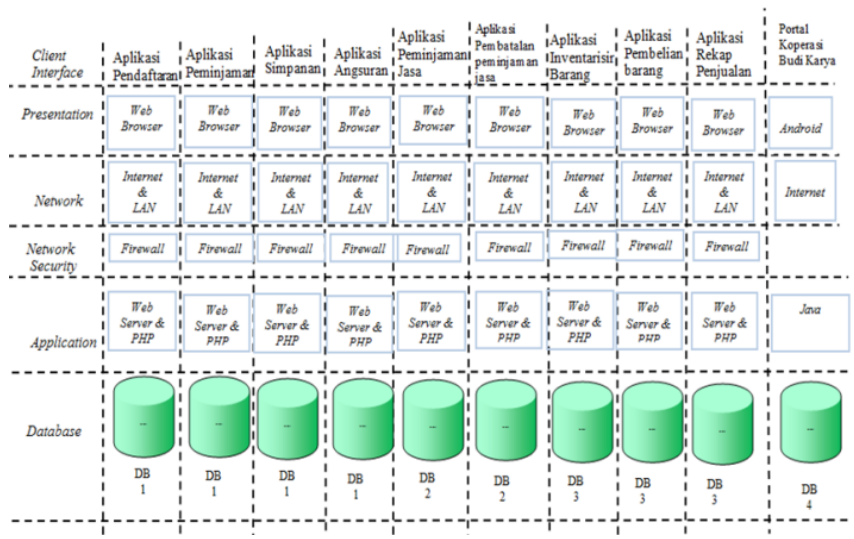

Gambar 10. Platform Decomposition Diagram

\subsection{VALIDASI}

Pada phase sebelumnya telah dilakukan analisis terhadap kondisi saat ini di Koperasi Budi Karya lalu dibuat rancangan arsitektur enterprise dengan metode TOGAF untuk usulan pada Koperasi Budi Karya tersebut. Selanjutnya, pada tahapan ini akan dilakukan analisis gap kondisi saat ini di Koperasi Budi Karya terhadap usulan arsitektur enterprise yang dibuat untuk memvalidasi arsitektur yang akan diusulkan. Pada tabel dibawah ini akan menggambarkan komponen-komponen apa saja yang dipertahankan (retain), dihilangkan (remove), diganti (replace) atau ditambahkan (add). Namun karena kondisi Koperasi Budi Karya yang sama sekali tidak memiliki sistem terkomputerisasi, maka pada tabel dibawah ini menyatakan semua aplikasi yang diusulkan adalah aplikasi yang ditambahkan (add). Tidak ada aplikasi yang dipertahankan (retain), dihilangkan (remove), atau diganti (replace).

TABEL XI. ANALISIS GAP UNTUK VALIDASI

\begin{tabular}{|c|c|c|c|c|c|c|c|c|c|c|}
\hline Exiting & 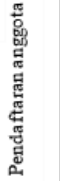 & 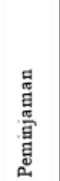 & 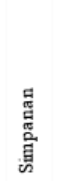 & $\begin{array}{l}\text { 焉 } \\
\text { 总 } \\
\text { 号 }\end{array}$ & 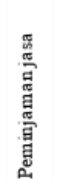 & 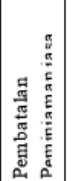 & 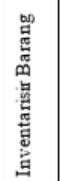 & 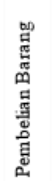 & 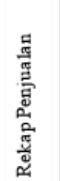 & 曼 \\
\hline New & Add & Add & Add & Add & Add & \begin{tabular}{|l|} 
Add \\
\end{tabular} & Add & Add & Add & \\
\hline
\end{tabular}

Pada Tabel XI diatas komponen yang sedang berjalan (exiting) ditempatkan pada kolom pertama paling kiri. Karena saat ini tidak ada sistem yang sedang berjalan maka isi dari komponen yang sedang berjalan (exiting) hanya New. Pada komponen usulan (future) berisi aplikasi yang diusulkan berdasarkan pada analisis enterprise arsitektur menggunakan TOGAF. Terdapat 9 (sembilan) aplikasi yang diusulkan pada Koperasi Budi Karya yaitu, Pendaftaran anggota, peminjaman, simpanan, angsuran, peminjaman jasa, pembatalan peminjaman jasa, inventarisir barang, pembelian barang dan rekap penjualan. Semua komponen usulan (future) ditandai dengan keterangan "add".

\section{KESIMPULAN DAN SARAN}

\subsection{KESIMPULAN}

1. Koperasi Budi karya dalam proses bisnisnya belum menggunakan sistem informasi dan teknologi informasi. Semua kegiatan pengelolaan data yang berhubungan dengan proses bisnis masih menggunakan cara manual. Maka pada penelitian ini membuat perancangan enterprise arsitekturr menggunakan framework TOGAF agar dapat menyelaraskan dengan misi Koperasi Budi Karya yaitu "Mengadopsi perkembangan teknologi informasi dan sistem manajemen modern". Arsitektur enterprise yang dihasilkan yaitu aktivitas bisnis, data, aplikasi dan teknologi pada Koperasi Budi karya.

2. Pada arsitektur sistem informasi didapatkan 9 aplikasi dari 3 divisi yang menjadi aktifitas utama pada Koperasi Budi karya yaitu aplikasi pendaftaran anggota, aplikasi peminjaman, aplikasi simpanan dan aplikasi angsuran yang menjadi proses bisnis divisi Simpan pinjam. 
Aplikasi peminjaman jasa dan aplikasi pembatalan peminjaman jasa yang menjadi proses bisnis divisi jasa. Dan terakhir aplikasi inventarisir barang, aplikasi pembelian barang dan aplikasi rekap penjualan yang menjadi proses bisnis divisi usaha.

3. Serta dalam hasil akhir untuk analisis GAP untuk validasi pada rancangan teknologi informasi togaf pada koperasi Budi Karya hanya menambahkan komponen Karena saat ini tidak ada sistem yang sedang berjalan maka isi dari komponen yang sedang berjalan (exiting) hanya New.

\subsection{SARAN}

1. Pada penelitian selanjutnya, diharapkan phase TOGAF dilanjutkan sampai phase Architecture Change Management agar pengimplementasian arsitektur mendapatkan model arsitektur enterprise yang lebih lengkap.

2. Diharapkan pada tahap pembuatan aplikasi dilaksanakan secara bertahap agar sesuai dengan tahapan analisis yang telah dilakukan.

3. Diharapkan pada setiap perancangan untuk menambah rancangan setiap support activity (aktivitas pendukung) yang telah dianalisis pada penelitian ini. Karena pada penelitian ini hanya berfokus pada primary activity (aktivitas utama)

4. Setelah menyelesaikan setiap arsitektur enterprise menggunakan TOGAF, diharapkan dapat membuat pengukuran ROI (return of investment) yang dapat digunakan sebagai analisis biaya investasi oleh Koperasi Budi karya.

\section{DAFTAR PUSTAKA}

[1] Harja, D. M., \& Anjarwani, S. E. Sistem Informasi Koperasi Pegawai Negeri ( KPN ) Universitas Mataram Berbasis Web. Journal of Computer Science and Informatics Engineering (J-Cosine), 2(2), 143-149, 2018.

[2] The Open Group. TOGAF Version 9.1. San Fransisco : The Open Group, 2009.

[3] Riyadi, S., Soedijinno, B., \& Amborowati. Pemodelan Enterprise Architectur Pelayanan di RSUD Murjani Sampit, 2015.

[4] Nugroho, S. J. Analisis dan pengembangan Enterprise Planning Sistem Informasi RSIA ANDINI dengan menggunakan TOGAF, 2012.

[5] Nusa, S. P. L. Perancangan Arsitektur Enterprise Untuk Koperasi Pertanian Menggunakan Enterprise Architecture Planning (Studi Kasus: Koperasi Produksi Susu Bogor), 2016.

[6] Khairuddin. Pembuatan Enterprise Architecture Planning Dinas Kebudayaan Provinsi Diy Dengan Menggunakan Kerangka Zachman, 2014.

[7] Bhaskoro, B. S. PERANCANGAN ARSITEKTUR SOFTWARE as a SEVICE (SaaS) RUMAH SAKIT, 2011.

[8] Popescu M. \& Dascalu A. Value Chain analysis in quality management context. Bulletine of the Transilvania University of Brasov. Volume 4 no 2, 2011.

[9] Ticoalu, voice esther. Peranncangan enterprise architecture menggunakan TOGAF ADM untuk mencapai universitas berbasis teknologi informasi (studi kasus: Unika De La Salle Manado), 2015.

[10] Harrison, Rachel. Study Guide TOGAF $^{\circledR} 9$ Foundation 2nd Edition. The Open Group, 2011. 